\title{
Living Arrangements and Social Support: Effects on the Well-Being of Mothers with Mental Illness
}

\author{
Carol T. Mowbray, Deborah Bybee, Leslie Hollingsworth, Sara Goodkind, and Daphna Oyserman
}

This article examines the effects of living arrangements on the well-being of mothers with a serious mental illness. Analyses of data from a National Institute of Mental Health-funded study of an urban, primarily African American sample of 379 mothers with mental illness revealed few differences in parenting or social functioning between mothers living with their children and a spouse or partner and those living with their children only. However, mothers

living with their children and extended family had significantly better outcomes than women in the other two living arrangements. Structural equation modeling analyses indicated that living with relatives significantly related to mothers' well-being (social functioning and parenting) above and beyond relatives' provision of social support. Multilevel modeling revealed racial differences in the effects of living with relatives on functioning and parenting stress: Effects were positive for African American mothers but mixed for white American mothers.

KEY WORDS: extended family; mental illness; mothers; psychiatric disabilities; social support

$\mathrm{M}$ otherhood is an important role for many women - one associated with numerous rewards and positive experiences, as well as arduous responsibilities and stresses, in that mothers often maintain the primary responsibility for their children (Larson \& Richards, 1994). However, fathers and other relatives can and do play significant roles in children's lives and in alleviating mothers' duties and pressures. Indeed, living arrangements and marital status are key predictors of mothers' well-being, with many studies concluding that married mothers are better off than their single counterparts (Coombs, 1991; Davies, Avison, \& McAlpine, 1997). However, other researchers have concluded that the aloneness of mother (that is, absence of supportive adults), more than particular family structure or living situation, is associated with reduced global well-being (Demo \& Acock, 1996). Living with relatives may promote the well-being of mothers through provision of increased support; for example, mothers who receive more emotional support have been found to be more nurturing in their parenting (Weinraub \& Wolf, 1983). Living with extended family appears to have especially positive effects for some sub-populations; for example, in black families, kin networks have heightened importance (Stack, 1974). Living arrangements and family support can also be significant for mothers who are at risk of problems in parenting or well-being.

Women with mental illnesses who are mothers are at risk of parenting and other functioning problems (see review by Oyserman, Mowbray, AllenMeares, \& Firminger, 2000). However, most of this research has focused on clinical variables as predictors, such as diagnosis, chronicity, and age of onset. Very little research has investigated the contributions of contextual features, such as living arrangements, which may be more malleable and subject to intervention than clinical history. In mental health services, clients' living arrangements are seen as important factors in recovery, evidenced by supported housing initiatives (Carling, 1995).

However, living arrangements are often confounded with family support (both positive and negative) and differ for African American and white families; therefore, analyses of living arrangements of mothers with mental illness must also attend to 
the effects of race and social support. Because research focused specifically on mothers with a mental illness is sparse, our literature review includes research on the effects of living arrangements and social support on the well-being of other groups of at-risk mothers as well.

\section{THE EFFECTS OF LIVING ARRANGEMENTS}

For adolescent mothers, policymakers have presumed that coresidence with family is beneficial, as evidenced by the requirements of the Personal Responsibility and Work Opportunity Reconciliation Act of 1996 (P.L. 104-193), but research results are mixed. One study found that for low-income teenage mothers, living with biological parents was associated with having congruent expectations and aspirations (Hellenga, Aber, \& Rhodes, 2002). Others have reported no effects (Kalil, Spencer, Spieker, \& Gilchrist, 1998) or negative effects of coresidence (Caldwell,Antonucci,Jackson,Wolford, \& Osofsky, 1997; Chase-Lansdale, Brooks-Gunn, \& Zamsky, 1994; Nitz, Ketterlinus, \& Brandt, 1995).

Mothers with mental illness are often single, living alone with their children, and in poverty - all of which can exacerbate symptoms (Rogler, 1996) and be risk factors for child outcomes (McLoyd \& Wilson, 1990). Thus, mothers with mental illness who are single parents could be expected to function less well than their married counterparts because of role overload, financial problems, and so forth. Living with extended family has not been studied for mothers with mental illness-a significant gap, given that these women may be more likely to live with their families due to lower marriage rates and higher divorce rates (Goldman, 1982; Lehman, Ward, \& Linn, 1982). Research on single adults with mental illness who live at home suggests that their family environments often differ significantly. In families with a member who has a mental illness, "expressed emotion" (critical or hostile comments or emotional over-involvement) predicted relapse in schizophrenia and mood disorders (Butzlaff \& Hooley, 1998). Thus, we might expect that living with extended families would have some negative effects on mothers with mental illness.

\section{THE BENEFITS OF SOCIAL SUPPORT}

For low-income single mothers, social support reportedly reduces the impact of stressful life events, like poverty, on psychological adjustment
(Goodman \& Johnson, 1986; Kessler \& McLeod, 1985). For teenage mothers, consistently significant positive relationships have been found between family social support and outcomes, whereas lack of family support (Turner, Grindstaff, \& Phillips, 1990; Unger \& Cooley, 1992;Voran \& Phillips, 1993) and conflictual family relationships (Thompson \& Peebles-Wilkins, 1992) relate to poor adjustment (Barth \& Schinke, 1983; Nitz et al., 1995). However, social support can be either positive (supporting) or negative (stressing) (Belle, 1982).

Many married women with mental illness report high levels of marital conflict and family strife (Mowbray et al., 2000; Ritsher, Coursey, \& Farrell, 1997) and may have spouses with psychiatric disorders (Miller, 1997) that could exacerbate their own functioning problems. Thus, the relationship between living with a spouse or partner and social support cannot be assumed for women with mental illness. Salokangas (1997) found that for men with schizophrenia, living with a spouse or parents contributed positively to outcomes, but the reverse was true for female patients. Furthermore, it is reportedly difficult for many women with mental illness to sustain family relationships (Nicholson \& Blanch, 1994; Ritsher et al.). Because mothers with mental illness often experience greater family conflict and social isolation (Downey \& Coyne, 1990), they may receive less social support from family members even when they are living with them than is the case for other mothers (Caron, Tempier, Mercier, \& Leouffre, 1998; Puckering, 1989).

Extended family support for parenting has not been studied in mothers with mental illness, nor has its effects on functioning or well-being. An exception is qualitative research by Nicholson, Sweeney, and Geller (1998), who found that positive family support is an asset for mothers with mental illness (and lack of support a liability), especially for those living in poverty, but that there is often conflict with family members, particularly over the parenting role.

\section{RELATIONSHIP BETWEEN SOCIAL SUPPORT AND LIVING ARRANGEMENTS}

Although research has examined the impact of social support or living relationships on the outcomes for at-risk mothers, the relationship between the two constructs has not been examined, with some exceptions. Both Chase-Lansdale and colleagues (1994) and Nitz and colleagues (1995) reported 
that parental support positively affected teenage mothers' parenting and reduced stress levels, but only when parents and teenage mothers did not coreside. Henly (1997) studied adolescent mothers and the reciprocal relationships between living arrangements and various types of support. She concluded that, for these young mothers, living arrangements were less important to psychological adjustment than were emotional and material support. Henly's study did not examine the role of negative support, which, in many studies, has been found to have an even greater impact on well-being than positive support (Rook, 1984; Todd \& Worell, 2000; Vinokur \& van Ryn, 1993).

\section{DIFFERENTIAL EFFECTS OF RACE AND ETHNICITY}

Living arrangements and family support may have qualitatively different influences in the lives of mothers from different racial or ethnic groups. For the most part, research suggests more benefits of coresidence in African American than in white American households, because the former emphasize cooperation among family members and involvement in decision making in times of distress (Finley, 1998). Congruent with this evidence, African American compared with white American adolescent mothers reported less conflict with their parents (Caldwell et al., 1997); for white American (but not African American) adolescent mothers, living with mothers related to more stress and worse parenting outcomes (Spieker \& Bensley, 1994; Unger \& Cooley, 1992), with some exceptions (Caldwell, Antonucci, \& Jackson, 1998). Henly (1997) also found that the effects of specific types of family support differ by race.

In populations with mental illness, it appears that African Americans with mental illness, compared with non-Hispanic white Americans, are more likely to live with extended family and to rely on informal networks for help (Guarnaccia, 1998), although a statewide study in California found no significant differences (Snowden, Libby, \& Ma, 2001). According to Barrio (2000), family members may be an important source of support for mentally ill women of color. Thus, it could be expected that social support and living arrangements have differential impacts in the lives and functioning of mothers with mental illness across racial and ethnic groups.

Thus, for at-risk mothers, the effects of living with extended family appear to depend on the extent to which such arrangements relate to positive or negative support, the nature of the support, and the mother's race or ethnicity (Chase-Lansdale, Gordon, Coley, Wakschlag, \& Brooks-Gunn, 1999; Henly, 1997). Studies suggest that positive support from family is independent of negative support and conflict, highlighting the necessity of examining positive and negative support separately. These results indicate a need for larger scale studies of the relationship of living arrangements and social support (both positive and negative) to functioning, well-being, and parenting for mothers with mental illness.

\section{HYPOTHESES}

Based on the literature previously reviewed, we hypothesized that for mothers with mental illness,

- those living with only their children will display worse outcomes (more symptoms, worse everyday functioning, and more parenting problems) than mothers living with children and partners or extended family

- mothers' outcomes will be influenced by amount and type of perceived social support, with negative support having the strongest influence

- once social support from relatives is accounted for, mothers' living arrangements will not explain any significant additional variability in the outcome measures

- the effects of living arrangements on outcomes will differ by race, as living with extended family is often more normative for African Americans (in white American families there may be different expectations and different types of support provided).

Using data from an NIMH-funded, longitudinal study of low-income mothers with serious mental illness who were receiving services from the public mental health system, we examined the impact of living arrangements on well-being, by comparing three groups - mothers living with only their children, mothers living with their children and husbands or partners, and mothers living with their children and extended family. Based on these results, we used structural equation modeling (SEM) to examine the impact of living arrangements and different types of support from relatives on the symptomatology, functioning, and parenting of these 
mothers. Including measures of living arrangements and of types of social support allowed us to examine the impact of the former, while controlling for effects of the latter. Multi-group SEM then enabled comparison of the differential impact of these factors for African American and white American mothers.

\section{METHOD}

\section{Sample}

Seriously Mentally Ill Women: Coping with Parenting is an NIMH-funded study of mothers with mental illness. The study was conducted with the collaboration of the local Community Mental Health (CMH) Agency following Agency and University Institutional Review Board approval. Women were systematically recruited from 12 $\mathrm{CMH}$ centers and from the inpatient psychiatric units of three hospitals in southeastern Michigan. To be eligible, women had to be between 18 and 55 years of age, have care responsibilities for at least one child age 4 to 16 , have a severe mental illness (for example, major affective or bipolar disorder, schizophrenia/schizoaffective), persisting for at least one year and producing major dysfunction in one or more life areas, and be an active case. At study initiation, all eligible participants on the agency rolls were identified by a research project liaison, using information from agency staff and agency management information systems. Of the 485 women identified, 46 could not be contacted or scheduled and 59 refused to be involved. Thus, 380 women were enrolled $(78.4 \%)$. One woman died between time of enrollment and the scheduled interview, leaving 379 participants. All women were offered $\$ 30 \mathrm{com}$ pensation for participation at baseline.

The analyses reported here excluded data from a subsample of women who did not live with their children, who only completed part of the interview, and whose diagnoses could not be ascertained. The characteristics of the resulting sample $(N=$ $307)$ included in the analyses reported here were 65.5\% African American, 33.9\% non-Hispanic white American, and $0.7 \%$ Latina. Except for an intentional overrepresentation of Latinas, the racial and ethnic identities of the study participants reflected the composition of the population in treatment in the public mental health system in the catchment area. The median family income was $\$ 1,161$ per month, with $64.6 \%$ of participants living below the poverty line. In terms of education,
$31.6 \%$ had less than high school education, $24.4 \%$ had a high school diploma or GED, and $44.0 \%$ had some college education or more. Participants' median age was 36.6 years. Median number of children per family was three, ranging from one to nine. (See also Mowbray et al., 2000).

\section{Measures}

Trained interviewers administered a comprehensive two-part interview. The first part covered demographics, personal history, social context, symptomatology, and functioning. The second part, administered within approximately one week, contained modules of the Diagnostic Interview Schedule (NIMH, 1980), sections from the Addiction Severity Index (McLellan, Luborsky, Woody, \& O'Brien, 1980), and questions about drug use.

IndependentVariable —Living Arrangements. For these analyses, participants were grouped as follows: women living with their children and no other adults (48.0\%); those living with children and a husband, boyfriend, or romantic partner $(32.2 \%)$; those living with their children and with extended family, and not living with a partner $(14.8 \% ; 8.4 \%$ lived with parents and $6.4 \%$ lived with other relatives). Women living alone $(5.0 \%)$ were omitted from analyses because of the small size of the group.

Demographics. Education was reported in years completed $(M=11.90, S D=2.28)$. To calculate adjusted household income, total monthly income as reported by participants $(M=\$ 1,094, S D=\$ 661)$ was expressed as a percentage of the poverty line (U.S. Census Bureau, 1997), adjusting for household size $(M=94 \%, S D=57)$.

The number and ages of children that mothers are responsible for can be a significant factor in analyses of supports and stresses. Women in the sample had from one to nine children, ages one to 17 , as well as adult children living with them. To examine the effects of children's age, a simple average of the children's ages inadequately represents mothers' family circumstances. Thus, families were categorized into one of the following children's age groupings (based on cluster analysis): mothers living with primarily pre- and elementary school-age children ( $n=107)$; mothers living with primarily middle school-age children $(n=78)$; mothers living with primarily high school-age and adult children $(n=122)$, and mothers living with no children $(n=35)$. To capture simultaneously the diversity of both age and number of children, we 
used cluster analysis, a statistical technique that sorts cases into clusters or groups that are as similar within as possible and as distinct from other clusters as possible (Hair \& Black, 2000). Specifically, a hierarchical agglomerative method (Ward's method, which minimizes within-cluster sums of squares, on squared Euclidean distances) was used to sort families on the basis of the number of children in each of 12 age groups (for example, less than 2,2$3,4-5, \ldots 20-21$, over 21). The optimal number of distinguishable cluster groupings (four) was determined through plots of fusion coefficients and examination of between-cluster differences (Aldenderfer \& Blashfield, 1984).

Clinical History. From the Diagnostic Interview Schedule (NIMH, 1980), diagnoses were major affective disorders (50.4\%), schizophrenia and related disorders $(22.7 \%)$, and mixed affective-psychotic disorders $(27.9 \%)$. For analyses, diagnosis was dichotomized into major affective versus any psychotic disorder, as this is a common distinction in the literature and several review articles have focused on the significance of affective disorders for parenting (for example, Downey \& Coyne, 1990). Duration of mental illness, calculated by subtracting age at onset of psychiatric disorder (indicated by age at first psychiatric hospitalization, or, if none, age at first psychiatric visit or worst symptoms) from current age, was measured in years $(M=10.38, S D$ $=7.54)$.

Social Context. Financial worries were measured with eight yes-no items which were summed, asking whether in the past three months participants had to worry about having enough money to pay for items such as food, clothing, rent, health care, and transportation $(M=3.91, S D=2.55$, range 0 8). Hassles (Hassles and Uplifts Scale, Lazarus \& Folkman, 1984), was an 18-item four-point scale ranging from $1=$ not a hassle at all to $4=$ a great deal of hassle, which indicates the extent to which daily hassles (for example, things breaking down in the house) are a source of stress $(M=2.81, S D=$ 49). Negative life events (Brief Life Events Questionnaire, Brugha \& Cragg, 1990) was a 21-item (yes-no) checklist of whether negative events (for example, major money crisis, sexual or physical assault, or death in the family) had occurred in the past year $(M=6.06, S D=3.3)$.

Social Support. The Arizona Social Support Interview Schedule (Barrera, 1996) is a measure of support of various types (Henly, 1997; Snowden,
2001). Participants were asked to list people important to them and then to indicate those both available and used for emotional support, material assistance, and child care assistance, and also to indicate people who made them upset or angry (negative support). Positive social support tabulated the number listed in all positive support domains $(M=$ $4.19, S D=.80$, range $0-5$ ). Because the SEM analysis focused on specific types of social support from the extended family, counts for the social support variables included only parents and other extended family members: Instrumental support (child care), $M=$ $1.32, S D=1.37$, range $0-9$; material support, $M=$ $1.66, S D=1.69$, range $0-12$; and emotional support, $M=1.66, S D=1.35$, range $0-6)$. The measure of negative support and stress included the number of extended family members with whom participants typically have unpleasant disagreements or who make them angry or upset (Barrera, 1988) $(M=$ $1.07, S D=1.46$, range $0-10$ ) as well as reports of hassles caused by parents and relatives (Lazarus \& Folkman, 1984). All items were standardized and then summed to constitute the measure $(M=-.04$, $S D=2.15, \alpha=.70$ ).

Current Mental Health and Functioning. Symptomatology was assessed with the Colorado Symptom Index (Shern, Wilson, \& Coen, 1994), a 14item, five-point symptom frequency scale ranging from $1=$ never $/$ not at all in the last year to $5=$ at least every day/most of the time, measuring both depressive and psychotic symptoms $(M=2.77, S D$ $=.83, \alpha=.90)$. Functioning in everyday life was measured with an 18-item, self-report Likert scale that included items related to daily chores, handling finances and crises, social activity and conflict, and relationship with case manager and therapist (Bybee, Mowbray, \& Cohen, 1994) $(M=3.39, S D=.54, \alpha$ $=.80)$. Each item is answered along a five-point scale tailored to the content of the question where $1=$ no activity in the domain and $5=$ frequent independent activity in the domain. Work, school, and volunteer involvement was measured on an ordinal scale ranging from $0=$ no work, school, or volunteer activity to 7 = full-time work, school, and/ or volunteering) $(M=1.16, S D=1.57)$.

Parenting. For parenting stress we used the Parenting Stress Index (Abidin, 1997), a 14-item, five-point Likert scale ranging from $1=$ not at all to $5=$ very much $(M=2.51, S D=.78, \alpha=.86)$, which covers child adaptability, acceptability, demands and mood, parental attachment, and parental social isolation. 
Satisfaction with relationship with children was measured with an eight-item, five-point Likert scale ranging from $1=$ very dissatisfied to $5=$ very satisfied, adapted from the Parenting Sense of Competence Scale (Gibaud-Wallston \&Wandersman,1978), indicating participants'level of satisfaction with their parenting experiences $(M=4.00, S D=.79, \alpha=$ $.83)$.

\section{Analysis}

To test hypothesis 1 (differences in outcomes across living arrangements), analysis of variance compared mothers with children living with husbands, boyfriends, or partners $(n=97)$, mothers and their children living with extended family $(n=42)$, and mothers living with only their minor children $(n=$ 168). Dependent variables were demographics, mental health history, current symptomatology, everyday functioning, social context, social support, and parenting. Because many of these variables may be confounded with age of children, the variable children's age group was included as a control (three categories: mothers who lived with pre- and elementary school-age children, mothers who lived with middle school-age children, and mothers who lived with high school-age and adult children). The sample size was sufficient only to contrast African American and white American mothers. Thus the analysis was a three-way analysis of variance (ANOVA) - living arrangements by race by children's age group. Following the recommendations of Hancock and Klockars (1996) and Wilcox (1987), paired tests (specifically, Games-Howell paired comparisons when variances were not equal and Tukey when variances were not significantly different) were used to compare means for the three types of living arrangements, regardless of the significance of the overall $F$.

For the multivariate prediction of outcome variables (hypotheses 2 and 3), we conducted analyses using SEM (Bollen, 1989) to estimate the equivalent of a multivariate multiple regression, simultaneously predicting three outcomes (parenting stress, symptomatology, and everyday functioning) from the type of situation in which the mother was living - extended family versus other arrangements and from positive support provided by relatives in each of three domains (emotional support, material support, and child care support), as well as negative support and stress from relatives. To account for potentially confounding effects related to living arrangements, the following control variables were included: education and income, children's age group (as two dummy variables with high school/ adult children as the contrast category), mental illness duration, and diagnosis (depression versus other).

For hypothesis 4 (whether the effects of living arrangements on outcomes differed by race), SEM provided a way to formally test the equivalence of modeled relationships for African American and white American mothers, using multigroup modeling. Modeling was done with AMOS 4 software (Arbuckle \& Wothke, 1999), using maximum likelihood estimation. Model fit was assessed through the following indices and thresholds suggested by $\mathrm{Hu}$ and Bentler $(1998,1999)$ : standardized rootmean-residual (SRMR) of .08 or smaller, rootmean-square error of approximation (RMSEA) of .06 or smaller, and incremental fit index (IFI) of .95 or greater. Model chi square is also reported, and the likelihood ratio (LR) chi-square was used to compare the fit of nested multigroup models with successively relaxed equality constraints.

\section{RESULTS}

\section{Comparison of Three Types of Living Arrangements}

The proportion of mothers in the three types of living arrangements differed significantly by race. Compared with African American mothers, white American mothers were more likely to be living with a husband, boyfriend, or partner $(51.9 \%$ versus $21.2 \%$ ); African American compared with white American mothers were more likely to live with extended family $(15.8 \%$ versus $9.6 \%)$ or with only their children $(63.1 \%$ versus $38.5 \%) ;\left[\chi^{2}(2, N=307)\right.$ $=30.07, p<.001]$.

In three-way analysis of variance- - living arrangements by race by children's age group-racial differences were found on income, number of children, work/school/volunteer involvement, financial worries, number of stressful life events, satisfaction with relationship with children, and positive social support (see Table 1). African American mothers had more children, on average, than white American mothers; more positive social support; and greater satisfaction with their relationships with their children. White American mothers reported higher income, more work/school/volunteer involvement, more financial worries, and more stressful life events. Few main effects were found for children's age 


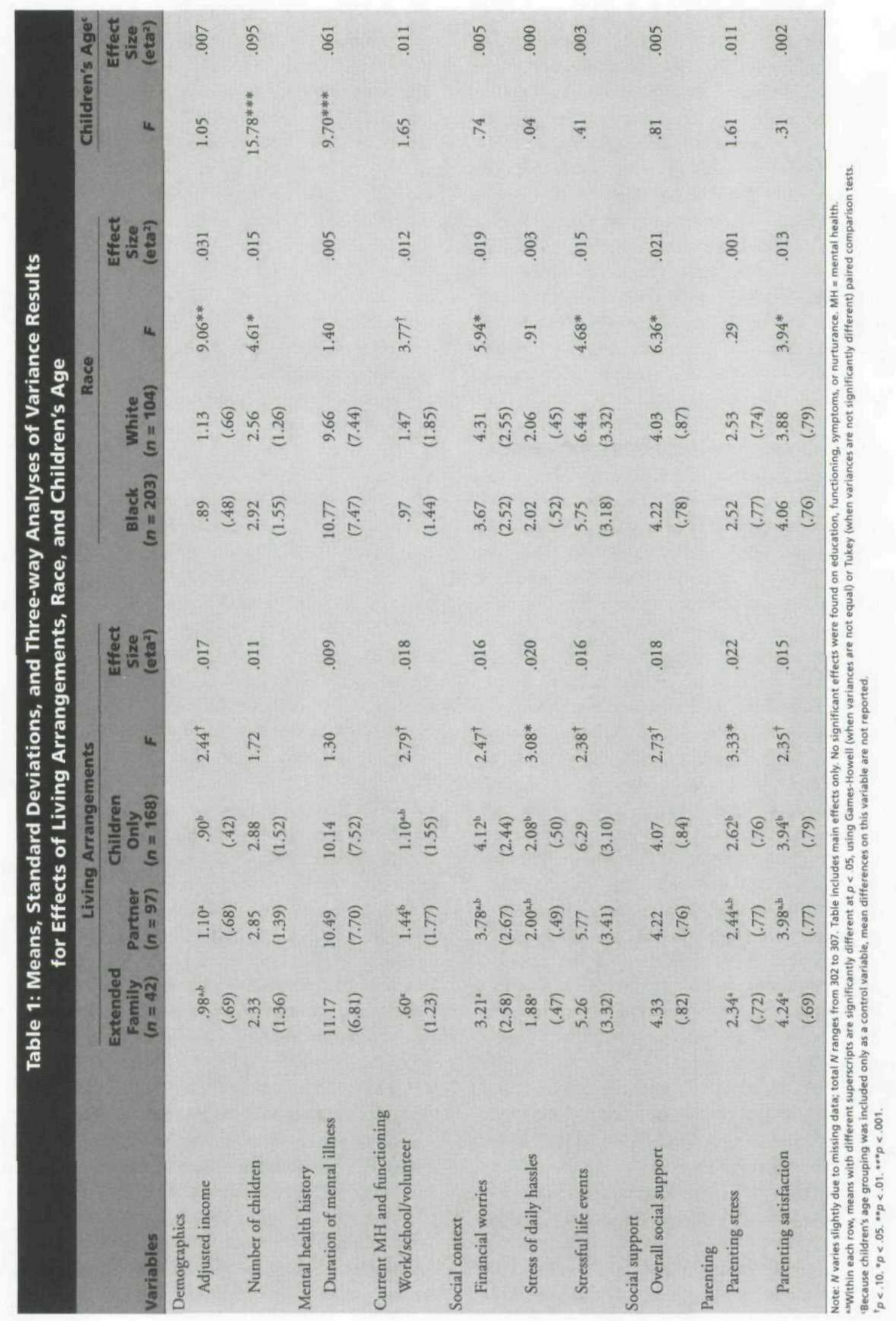


grouping. Because this variable was not of central interest, these differences are not reported.

Controlling for the effects of race and children's age group, the three-way ANOVA testing hypothesis 1 showed main effects for living arrangements on income, work/school/volunteer involvement, financial worries, hassles, parenting stress, and satisfaction with child relationships. Mothers living with partners had higher incomes than those living with only their children. Those living with relatives had less work/school/volunteer involvement than those living with partners. They also had fewer financial worries, less stress from hassles, and less parenting stress and experienced greater satisfaction with child relationships than those living with only their children.

\section{Structural Equation Model (SEM) Relating Living Situation to Well-Being}

SEM was used to examine the relationship between mothers' outcomes and living with relatives (versus living with only their children, or living with partners), controlling for the effect of specific types of family support as well as demographic and clinical history variables, testing hypotheses 2 and 3 . Means, standard deviations, and inter-correlations of the variables used in this analysis are reported separately for African American and white American mothers in Table 2. An SEM analogous to a fully-specified multivariate multiple regression was initially fit to the data for the sample as a whole. In this model, all paths from the independent variables to the three outcome variables (parenting stress, symptomatology, and everyday functioning) were estimated. Directional paths were specified among the three outcome variables, reflecting the assumption that symptomatology would exert effects on both everyday functioning and parenting stress and that functioning would affect parenting stress. Paths that were not significantly different from zero in the total sample or in either subgroup were sequentially fixed to zero; resulting in a trimmed model with no significant degradation in fit to the data $\left[\operatorname{LR} \chi^{2}(62, N=303)=47.610, p=\right.$ $.911, \mathrm{RMSEA}=.000, \mathrm{SRMR}=.037]$. The final model is in Figure 1.

In the final model, income and education were positively associated with everyday functioning, whereas education was negatively related to symptomatology. Duration of mental illness was also negatively associated with symptomatology. Hav- ing middle school-age children (compared with older, teenage children) related to lower levels of parenting stress. In terms of interrelationships of outcome variables, as assumed, symptomatology was positively related to parenting stress and negatively related to everyday functioning. Controlling for the effects of other variables in the model, everyday functioning and parenting stress were not significantly related. Related to hypothesis 2 , negative support and stress from relatives was positively related to symptomatology and negatively related to everyday functioning, controlling for demographic and clinical variables. Furthermore, confirming hypothesis 3 , living with relatives was significantly associated with lower symptomatology, even when the effects of demographics, clinical variables, and types of social support were taken into account.

To address hypothesis 4 (comparison of the modeled relationships by race), we estimated a multigroup model, with separate coefficients for African American $(n=201)$ and white American mothers $(n=102)$. This unconstrained multigroup model, with coefficients freely estimated within group, was a good fit to the data: $\chi^{2}(122, N=303)$ $=92.825, p=.977 ;$ RMSEA $=.000 ;$ SRMR $=$ .058. To compare the coefficients across the two groups, we constrained all structural parameter estimates to be equal between the two groups. The fit of this fully constrained model was then compared with the unconstrained model; the significant LR $\chi^{2}(30, N=303)=45.688, p=.033$ indicated the presence of significant parameter differences between the two groups. To identify these, we sequentially freed relevant constraints, beginning with the unstandardized coefficients with the largest absolute between-group difference in the unconstrained model, until the fit of the partially constrained model did not significantly differ from the unconstrained model. The coefficient freed first was for the path between living with relatives and parenting stress. Although comparative fit improved with this coefficient estimated separately for the two groups, fit remained significantly worse than for the unconstrained model [LR $\chi^{2}(29, N=303)$ $=42.687, p=.049]$. The coefficient for the path from living with relatives and everyday functioning had the next largest difference, followed by the coefficient from emotional support to everyday functioning. With these three coefficients estimated separately by race, the fit of the partially constrained model was not significantly worse than that of the 


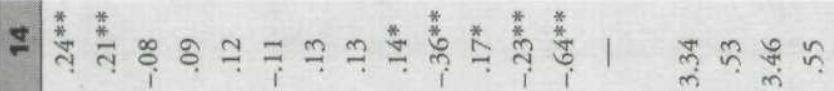

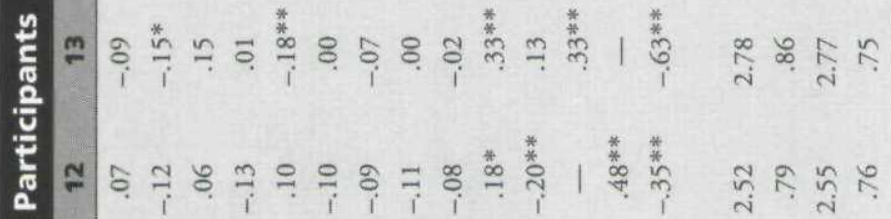

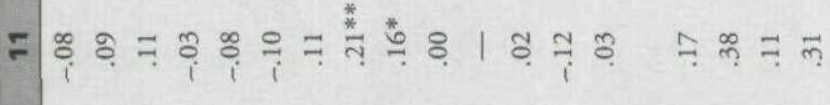

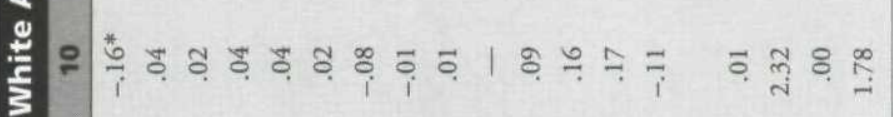

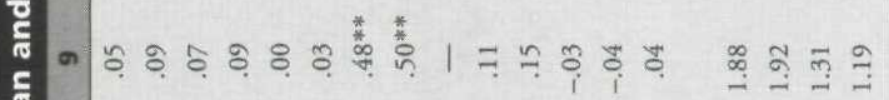

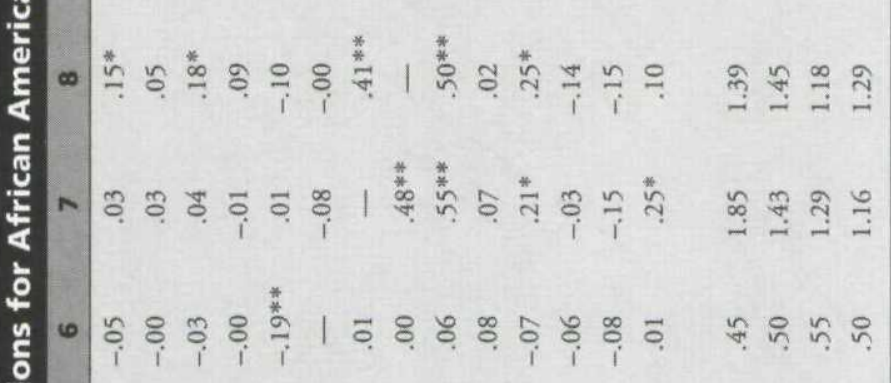

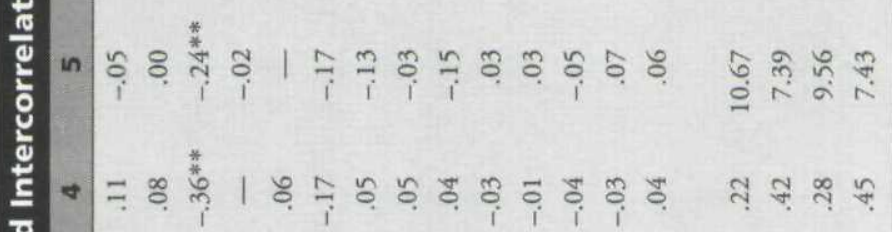
है

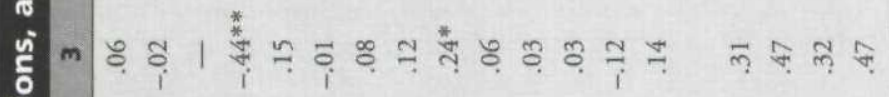

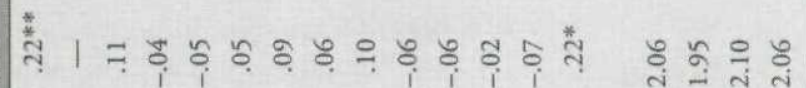
ที 댈 


\section{Figure 1: Relationships between Support, Living Arrangements, and Outcome Variables}

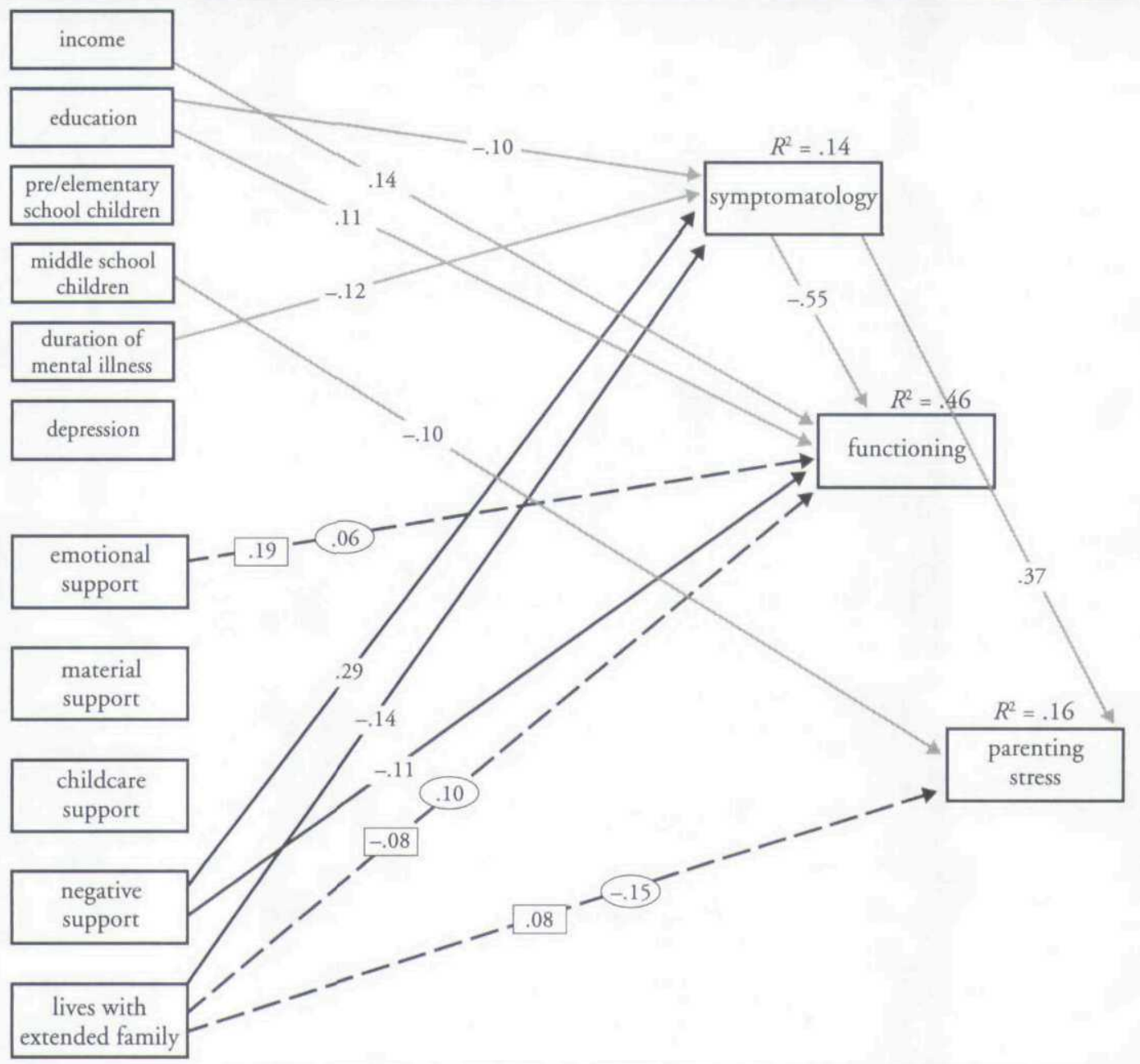

Notes: Thick pathway = hypothesized effect; thin pathway = demographidcontrol variable or relationship among outcome variables; dashed line = path differing significantly by race; circle $=$ African American coefficient; square $=$ white American coefficient.

unconstrained model $\left[\operatorname{LR} \chi^{2}(27, N=303)=38.427\right.$, $p=.071]$. Unstandardized coefficients and standard errors for the partially constrained multigroup model are presented in Table 3.

The three coefficients for which there were significant differences between African American and white American mothers were the association between living with relatives and parenting stress, living with relatives and everyday functioning, and emotional support from relatives and functioning. For African American mothers, living with relatives was associated with lower parenting stress and higher functioning. For white American mothers, the signs of these relationships were reversed, suggesting that living with extended family was asso- ciated with negative outcomes for this group. The relationships were not significant in the white American sample due to its smaller size, but they were significantly different from the relationships for African American mothers. In contrast, emotional support from relatives was positively related to functioning for white American mothers, but the association was not significantly different from zero in the African American group.

\section{DISCUSSION}

\section{Bivariate Relationships}

Contrary to our first hypothesis concerning living arrangements, in paired comparison ANOVA results, there were few differences between women 


\begin{tabular}{|c|c|c|c|c|c|c|}
\hline \multirow[b]{2}{*}{ Path } & \multicolumn{3}{|c|}{ African American } & \multicolumn{3}{|c|}{ White American } \\
\hline & Coefficient & SE & $\boldsymbol{p}$ & Coefficient & SE & $\boldsymbol{p}$ \\
\hline Income $\rightarrow$ Functioning & 0.124 & 0.043 & 0.004 & 0.124 & 0.043 & 0.004 \\
\hline Education $\rightarrow>$ Symptomatology & -0.043 & 0.023 & 0.06 & -0.043 & 0.023 & 0.06 \\
\hline Education $\rightarrow$ Functioning & 0.031 & 0.012 & 0.009 & 0.031 & 0.012 & 0.009 \\
\hline Middle school $\rightarrow$ Parenting stress & -0.168 & 0.095 & 0.078 & -0.168 & 0.095 & 0.078 \\
\hline Duration of MI $\rightarrow$ Symptomatology & -0.013 & 0.006 & 0.03 & -0.013 & 0.006 & 0.03 \\
\hline Emotional Support $->$ Functioning & 0.021 & 0.019 & 0.272 & 0.087 & 0.035 & 0.013 \\
\hline Negative support $\rightarrow$ Symptomatology & 0.109 & 0.021 & 0.001 & 0.109 & 0.021 & 0.001 \\
\hline Negative support $\rightarrow$ Functioning & -0.028 & 0.011 & 0.01 & -0.028 & 0.011 & 0.01 \\
\hline Lives with extended family $\rightarrow$ Symptomatology & y -0.323 & 0.124 & 0.009 & -0.323 & 0.124 & 0.009 \\
\hline Lives with extended family $\rightarrow$ Functioning & 0.14 & 0.072 & 0.05 & -0.133 & 0.132 & 0.313 \\
\hline Lives with extended family $\rightarrow$ Parenting stress & -0.313 & 0.135 & 0.02 & 0.191 & 0.211 & 0.365 \\
\hline Symptomatology $\rightarrow$ Functioning & -0.355 & 0.029 & 0 & -0.355 & 0.029 & 0 \\
\hline Symptomatology $\rightarrow$ Parenting stress & 0.354 & 0.05 & 0 & 0.354 & 0.05 & 0 \\
\hline
\end{tabular}

Note. All coefficients are unstandardized. Unconstrained paths (that is, those that differed significantly by race and were therefore estimated separately for African American and white women) are bolded; all others are constrained to equality between groups.

Model chi-square $=92.825, d f=122, p=.849 ;$ SRMR $=071 ;$ RMSEA $=0.00,|F|=99$.

living with a spouse or partner versus women living with only their children. This finding suggests that women with serious mental illness may not experience the beneficial effects of an intimate heterosexual relationship, as seems to be the case in the general population. Results from other analyses with this sample suggest support for this interpretation: hassles with a romantic partner were reported by about half of the women, and $60 \%$ of the women identified the fathers of their children as a hassle (Mowbray et al., 2000); of course not all these women lived with the father of their children. Furthermore, in the current analysis, although mothers with partners had significantly higher adjusted incomes than mothers living with their children only, there were no differences between the two groups on financial worries, suggesting that economic strains were not alleviated by the presence of a spouse or partner in the household. These results are similar to results of other studies reporting that women with mental illness often have high levels of conflict in intimate relationships (Ritsher et al., 1997).Thus, it appears that assumptions about the positive consequences of mothers with mental illness living with a spouse or partner may be unwarranted, especially for low-income, urban women.

According to the ANOVA comparisons, mothers living with extended family appeared to have lower instrumental functioning (fewer engaged in activity outside the home); alternatively, they may have less need for work outside the home. On many other variables, these women expressed less distress and more satisfaction than women living with only their children. These results are rather striking, especially given the smaller number of women living with extended family.

Bivariate analyses also revealed very large and significant differences in living arrangements by race. Percentage-wise, white American mothers were more than twice as likely as African Americans to live with a spouse or partner. African American mothers were about 1.5 times as likely to live with only their children and about $50 \%$ more likely to live with extended family and children. U.S. Census data and other research reports also found that African Americans are more likely to reside in extended family households than are white Americans (Koebel \& Murray, 1999). Our findings are congruent with those of Guarnaccia (1998), who found that for mental health clients, African Americans are more likely than white Americans to live in extended family households. Contradictory findings from Snowden and colleagues (2001), reporting equal proportions of African American and white American clients with mental illness living with extended family, apparently reflect characteristics unique to their California sample (that is, 
multigenerational poverty or the mobile nature of the population). Given that gender effects of living arrangements have been reported to be significant (Salokangas, 1997), differences may also reflect their mixed gender sample.

\section{Living Arrangements and Social Support: Multivariate Findings}

Results of the SEM indicated that, for the entire sample of mothers, demographic and clinical variables all had significant relationships with outcomes (with the exception of diagnosis - a result frequently reported for adults with long-term mental illness; Anthony, 1994). This confirms the importance of including these factors as control variables. Our second hypothesis, concerning social support, was only partially validated: for the positive support variables, there were no significant relationships between outcomes and family-provided material or child care support once the effect of living arrangements and negative support were accounted for. Emotional support from relatives was associated with better everyday functioning, but only for white Americans. On the other hand, negative support had strong and consistently significant effects on symptomatology and everyday functioning for both African American and white American mothers. Other studies have also found that results differ when comparing positive (family support for parenting) versus negative support (family conflict over childrearing practices) (Caldwell et al., 1998). According to Richardson and colleagues (1991), support and interference are two separate dimensions of social networks, not opposite ends of a single continuum. The fact that negative support and stress had a greater impact than did positive support indicates the importance of measuring these types of support separately, as the presence of one does not necessarily indicate the absence of the other.

Contrary to our third hypothesis, living arrangements continued to show significant relationships with the outcome variables, even when accounting for social support, clinical, and demographic variables. Specifically, living with relatives was associated with reduced symptomatology for both African American and white American participants. In contrast, Henly (1997) concluded that support was more significant in the lives of adolescent mothers than living arrangements. These disparities may reflect differences between the two target populations, which are substantial, and in the measure- ment of social support. (The current study assessed negative support, whereas Henley's did not.)

Finally, as stated in hypothesis 4, living with extended family related differently to functioning and parenting stress in African American and white American participants. For African Americans, living with extended family was associated with enhanced everyday functioning and reduced parenting stress. For the white American mothers, these relationships were significantly different and in the opposite direction (although slightly weaker and not significant within the smaller sample). Living with relatives appears to be more negative, stressful, and conflictual for white American mothers (as in Caldwell et al., 1997).

\section{Accounting for Interactions between Living Arrangements and Race}

Why would living with relatives relate to more positive outcomes for African Americans? Several explanations are possible, congruent with current literature on cultural differences. African American and white American families differ in the value of independence, social perceptions of extended family residence, and role sharing. Sudarkasa (1988) wrote that among African Americans the concept of family has been defined primarily in terms of blood (consanguineal) relationships rather than marital (conjugal) ones. In African American households there is greater acceptability of living with extended family once children are grown (Caldwell et al.,1997). Thus, African American mothers may experience less conflict in sharing the parenting role with their own mothers (Brown, 2000) and may be more likely to take advantage of the opportunity this sharing presents, thereby experiencing their lives as less stressful. In an adolescent sample, African American mothers who continued to live with their children in the households of their own mothers had more positive outcomes than those who lived independently (Wilson \& Tolson, 1990).

Cultural differences in the value of family may be relevant in other ways, as well:African American compared with white American families appear to be more valuing of the mothering role (McKelvey \& McKenry, 2000). Mothers of African American teenage mothers still consider their daughters to be children in the family (Caldwell \& Antonucci, 1997). This situation may generalize to race differences in treatment of daughters with disabilities, such as mental illness, and therefore to higher acceptance 
of incorporating a mother with mental illness and her children into an extended family household. Finally, in African American households, extended family members may put more pressure on young unmarried fathers to be involved with their children, thus taking some stress away from single mothers (Coley, 2001).

\section{CONCLUSION}

Contrary to the study hypothesis, we found that living arrangements had effects on well-being of mothers with mental illness, independent of family-provided social support (or demographic and clinical factors). These effects were consistently positive for African American mothers and were negative or nonsignificant for white American mothers in this study. Explanations suggested for these findings involve race differences in the meaning of family and the greater acceptability of mothers living with extended families in African American versus white American households.

The hypothesized significant effects of social support were partially confirmed. With the exception of emotional support having an effect on everyday functioning for white American women, none of the positive social support variables had significant effects on mothers' outcomes. On the other hand, negative support had significant effects on symptomatology and everyday functioning. Differences in the effects of positive versus negative support reinforce the importance of measuring and analyzing these constructs separately.

These results need to be replicated in larger samples and examined longitudinally, to further clarify the direction of effects. The study sample is representative of those served by the public mental health system in this urban area. However, it may not be representative of mothers with severe mental illness served in other cities or in suburban or rural settings, or of families above the poverty line whose incomes or insurance allow them to obtain private care. Also, the findings may reflect limitations in our measurement of social support (although the Barrera measure has been widely used). For now, the findings suggest that case management and counseling services for low-income mothers with a mental illness need to take into account family circumstances, like positive and negative social support, and cultural values when advising about the benefits of alternative living arrangements. Case managers and service planners should not assume negative effects for adults with serious mental illnesses living with their familiesespecially in the case of women with children. SWR

\section{REFERENCES}

Abidin, R. R. (1997). Parenting Stress Index: A measure of the parent-child system. In C. P. Zalaquett, \& R. J. Wood (Eds.), Evaluating stress: $A$ book of resources (pp. 277-291). Lanham, MD: Scarecrow Press.

Aldenderfer, M. S., \& Blashfield, R. K. (1984). Cluster analysis (Quantitative applications in the social sciences No. 44). Beverly Hills, CA: Sage Publications.

Anthony, W. A. (1994). Characteristics of people with psychiatric disabilities that are predictive of entry into the rehabilitation process and successful employment. Psychosocial Rehabilitation Journal, 17(3), 3-13.

Arbuckle, J. L., \& Wothke, W. (1999). AMOS 4.0 user's guide. Chicago: Small Waters.

Barrera, M. (1988). The Arizona Social Support Interview Schedule. In B. H. Gottlieb (Ed.), Social networks and social support (pp, 88-93). Beverly Hills, CA: Sage Publications.

Barrera M. (1996). Arizona Social Support Interview Schedule. Tempe,AZ: Arizona State University, Psychology Department.

Barrio, C. (2000). The cultural relevance of community support programs. Psychiatric Services, 51, 879-884.

Barth, R. P., \& Schinke, S. P. (1983). Coping with daily strain among pregnant and parenting adolescents. Journal of Social Service Research, 7, 51-63.

Belle, D. E. (1982). The impact of poverty on social networks and supports. Marriage \& Family Review, 5, 89-103.

Bollen, K.A. (1989). Structural equations with latent variables. New York: John Wiley \& Sons.

Brown, E. (2000). Mothering and parenting styles. In N.J. Burgess \& E. Brown (Eds.), African American women (pp. 53-82). New York: Falmer Press.

Brugha, T. S., \& Cragg, D. (1990). The list of threatening life experiences: The reliability and validity of a brief life events questionnaire. Acta Psychiatrica Scandinavica, 82, 77-81.

Butzlaff, R. L., \& Hooley, J. M. (1998). Expressed emotion and psychiatric relapse: A meta-analysis. Archives of General Psychiatry, 55, 547-552.

Bybee, D., Mowbray, C. T., \& Cohen, E. (1994). Short vs. longer term effectiveness of an outreach program for the homeless mentally ill. American Journal of Community Psychology, 22, 81-209.

Caldwell, C. H., \& Antonucci, T. C. (1997). Childbearing during adolescence: Mental health risks and opportunities. In J. Schulenberg, J. Maggs, \& K. Hurrelmann (Eds.), Health risks and developmental transitions during adolescence (pp. 220-245). New York: Cambridge University Press.

Caldwell, C. H., Antonucci, T. C., \& Jackson, J. S. (1998). Supportive/conflictual family relations and depressive symptomatology: Teenage mother and grandmother perspectives. Family Relations, 47, 395-402.

Caldwell, C. H., Antonucci, T. C., Jackson, J. S., Wolford, M. L., \& Osofsky, J. D. (1997). Perceptions of parental support and depressive symptomatology among black and European American adolescent mothers. Journal of Emotional and Behavioral Disorders, 5, 173-183.

Carling, P. (1995). Return to community: Building support systems for people with disabilities. New York: Guilford Press. 
Caron, J., Tempier, R., Mercier, C., \& Leouffre, P. (1998). Components of social support and quality of life in severely mentally ill, low-income individuals and a general population group. Community Mental Health Journal, 34, 459-475.

Chase-Lansdale, P. L., Brooks-Gunn, A., \& Zamsky, E. S. (1994). Young African-American multigenerational families in poverty: Quality of mothering and grandmothering. Child Development, 65, 373-393.

Chase-Lansdale, P. L., Gordon, R.A., Coley, R. L. Wakschlag, L. S., \& Brooks-Gunn, J. (1999). Young African American multigenerational families in poverty: The contexts, exchanges, and processes of their lives. In E. M. Hetherington (Ed.), Coping with divorce, single parenting, and remarriage: $A$ risk and resiliency perspective (pp. 165-191). Mahwah, NJ: Lawrence Erlbaum.

Coley, R. L. (2001). (In)visible men: Emerging research on low-income, unmarried, and minority fathers. American Psychologist, 56, 743-753.

Coombs, R. H. (1991). Marital status and personal wellbeing: A literature review. Family Relations, 40, 97102.

Davies, L., Avison, W. R., \& McAlpine, D. D. (1997). Significant life experiences and depression among single and married mothers. Journal of Marriage and the Family, 59, 294-308.

Demo, D. H., \& Acock, A. C. (1996). Singlehood, marriage, and remarriage: The effects of family structure and family relationships on mothers' wellbeing. Journal of Family Issues, 17, 388-407.

Downey, G., \& Coyne, J. C. (1990). Children of depressed parents: An integrative review. Psychological Bulletin, 108, 50-76

Finley, L.Y. (1998). The cultural context: Families coping with severe mental illness. Psychiatric Rehabilitation Journal, 21, 230-239.

Gibaud-Wallston, J., \& Wandersman, A. (1978, August). Development and utility of the parenting sense of competence scale. Paper presented at the meeting of the American Psychological Association, Toronto.

Goldman, H. H. (1982). Mental illness and family burden: A public health perspective. Hospital and Community Psychiatry, 33, 557-560.

Goodman, S. H., \& Johnson, M. S. (1986). Life problems, social supports, and psychological functioning of emotionally-disturbed and well low-income women. Journal of Community Psychology, 14, 150-158.

Guarnaccia, P. J. (1998). Multicultural experiences of family caregiving: A study of African American, European American, and Hispanic American families. New Directions for Mental Health Services, 77, 45-62.

Hair, J. F., Jr., \& Black, W. C. (2000). Cluster analysis. In L. G. Grimm \& P. R.Yarnold (Eds.), Reading and understanding more multivariate statistics (pp. 147-206). Washington, DC: American Psychological Association.

Hancock, G. R., \& Klockars, A. J. (1996). The quest for alpha: Developments in multiple comparison procedures in the quarter century since Games (1971). Review of Educational Research, 66, 269-306.

Hellenga, K., Aber, M. S., \& Rhodes, J. E. (2002). African American adolescent mothers' vocational aspiration-expectation gap: Individual, social and environmental influences. Psychology of Women Quarterly, 26, 200-212.

Henly, J. R. (1997). The complexity of support: The impact of family structure and provisional support on African-American and European American adolescent mothers' well-being. American Journal of Community Psychology, 25, 629-655.
Hu, L., \& Bentler, P. M. (1998). Fit indices in covariance structure modeling: Sensitivity to underparameterized model misspecification. Psychological Methods, 3, 424453.

Hu, L., \& Bentler, P. M. (1999). Cutoff criteria for fit indexes in covariance structure analysis: Conventional criteria versus new alternatives. Structural Equation Modeling, 6, 1-55.

Kalil, A., Spencer, M. S., Spieker, S. J., \& Gilchrist, L. D. (1998). Effects of grandmother coresidence and quality of family relationships on depressive symptoms in adolescent mothers. Family Relations, 47, 433-441.

Kessler, R. C., \& McLeod, J. D. (1985). Social support and mental health in community surveys. In S. Cohen \& S. L. Syme (Eds.), Social support and health (pp. 219240). Orlando, FL: Academic Press.

Koebel, C. T., \& Murray, M. S. (1999). Extended families and their housing in the U.S. Housing Studies, 14, 125-143.

Larson, R., \& Richards, M. H. (1994). Divergent realities: The emotional lives of mothers, fathers, and adolescents. New York: Basic Books.

Lazarus, R., \& Folkman, S. (1984). Stress, appraisal, and coping. New York: Springer-Verlag.

Lehman, A. F, Ward, N. C., \& Linn, L. C. (1982). Chronic mental patients: The quality of life issue. American Journal of Psychiatry, 139, 1271-1276.

McKelvey, M. W., \& McKenry, P. C. (2000). The psychosocial well-being of black and European American mothers following marital dissolution. Psychology of Women Quarterly, 24, 4-14.

McLellan, A. T., Luborsky, L., Woody, G. E., \& O'Brien, C. P. (1980). An improved diagnostic evaluation instrument for substance abuse patients: The Addiction Severity Index. Journal of Nervous and Mental Disorders, 168, 26-33.

McLoyd,V. C., \& Wilson, L. (1990). Maternal behavior, social support, and economic conditions as predictors of distress in children. New Directions for Child Development, 46, 49-69.

Miller, L. J. (1997). Sexuality, reproduction, and family planning in women with schizophrenia. Schizophrenia Bulletin, 23, 623-635.

Mowbray, C. T., Schwartz, S., Bybee, D., Spang, J., RuedaRiedle, A., \& Oyserman, D. (2000). Mothers with mental illness: Stressors and resources for parenting and living. Families in Society, 81, 118-129.

National Institute of Mental Health. (1980). Diagnostic Interview Schedule (DIS). Rockville, MD: Author.

Nicholson, J., \& Blanch, A. (1994). Rehabilitation for parenting roles in the seriously mentally ill. Psychosocial Rehabilitation Journal, 18, 109-119.

Nicholson, J., Sweeney, E. M., \& Geller, J. L. (1998). Mothers with mental illness II: Family relationships and the context of parenting. Psychiatric Services, 49, 643-649.

Nitz, K., Ketterlinus, R. D., \& Brandt, L. J. (1995). The role of stress, social support, and family environment in adolescent mothers' parenting. Journal of Adolescent Research, 10, 358-382.

Oyserman, D., Mowbray, C. T., Allen-Meares, P., \& Firminger, K. (2000). Parenting among mothers with a mental illness. American Journal of Orthopsychiatry, 70, 296-315.

Personal Responsibility and Work Opportunity Reconciliation Act of 1996, P.L. 104-193, 110 Stat. 2105.

Puckering, C. (1989). Annotation: Maternal depression. Journal of Child Psychology \& Psychiatry E Allied Disciplines, 30, 807-817.

Richardson, R. A., Barbour, N. B., \& Bubenzer, D. L. (1991). Bittersweet connections: Informal social 
networks as sources of support and interference for adolescent mothers. Family Relations, 40, 430-434.

Ritsher, J.E.B., Coursey, R. D., \& Farrell, E. W. (1997). A survey on issues in the lives of women with severe mental illness. Psychiatric Services, 48, 1273-1282.

Rogler, L. H. (1996). Increasing socioeconomic inequalities and the mental health of the poor. Journal of Nervous \& Mental Disease, 184, 719-722.

Rook, K.S. (1984). The negative side of social interaction: Impact on psychological well-being. Journal of Personality \& Social Psychology, 46, 1097-1108.

Salokangas, R.K.R. (1997). Living situation, social network and outcome in schizophrenia: A five-year prospective follow-up study. Acta Psychiatrica Scandinavica, 96, 459-468.

Shern, D. L., Wilson, N. Z., \& Coen, A. S. (1994). Client outcomes II: Longitudinal client data from the Colorado treatment outcome study. Milbank Quarterly, 72, 123-145.

Snowden, L. R. (2001). Social embeddedness and psychological well-being among African-Americans and European Americans. American Journal of Community Psychology, 29, 519-536

Snowden, L. R., Libby, A., \& Ma, Y. (2001, January). Family involvement, costs, and use of mental health services: Minority-European American differences. Paper presented at the Society for Social Work and Research Conference, Atlanta.

Spieker, S. J., \& Bensley, L. (1994). Roles of living arrangements and grandmother social support in adolescent mothering and infant attachment. Developmental Psychology, 30, 102-111.

Stack, C. B. (1974). All our kin: Strategies for survival in a black community. New York: Harper \& Row.

Sudarkasa, N. (1988). Interpreting the African heritage in Afro-American family organization. In H.P. McAdoo (Ed.), Black families (pp. 27-43). Newbury Park, CA: Sage Publications.

Thompson, M. S., \& Peebles-Wilkins, W. (1992). The impact of formal, informal, and societal support networks on the psychological well-being of black adolescent mothers. Social Work, 37, 322-328.

Todd, J. L., \& Worell, J. (2000). Resilience in low-income, employed, African American women. Psychology of Women Quarterly, 24, 119-128.

Turner, R. J., Grindstaff, C. F., \& Phillips, N. (1990). Social support and outcome in teenage pregnancy. Journal of Health \& Social Behavior, 31, 43-57.

Unger, D. G., \& Cooley, M. (1992). Partner and grandmother contact in black and European American teen parent families. Journal of Adolescent Health, 13, $546-552$.

U.S. Census Bureau. (1997, October 10). Poverty thresholds in 1996 by size of family and number of related children under 18 years. Retrieved from http://www.census. gov/hhes/poverty/threshld/thresh96.html

Vinokur, A. D., \& van Ryn, M. (1993). Social support and undermining in close relationships: Their independent effects on the mental health of unemployed persons. Journal of Personality and Social Psychology, $65,350-359$

Voran, M., \& Phillips, D. (1993). Correlates of grandmother childcare support to adolescent mothers: Implications for development in two generations of women. Children EYouth Services Review, 15, 321-334.

Weinraub, M., \& Wolf, B. M. (1983). Effects of stress and social supports on mother-child interactions in single- and two-parent families. Child Development, 54, 1297-1311.

Wilcox, R. R. (1987). New statistical procedures for the social sciences: Modern solutions to basic problems. Hillsdale, NJ: Lawrence Erlbaum.
Wilson, M. N., \& Tolson, T.F.J. (1990). Familial support in the black community. Journal of Clinical Child Psychology, 19, 347-355.

Carol T. Mowbray, PhD, is professor, School of Social Work, University of Michigan, 1080 South University, Ann Arbor,MI; e-mail:cmowbray@umich.edu.Deborah Bybee, $\mathrm{PhD}$, is associate professor, Department of Psychology, Michigan State University, Leslie Hollingsworth, PhD, ACSW, CSW, is associate professor, and Sara Goodkind, MSW, is a doctoral candidate in social work and sociology, School of Social Work, University of Michigan. Daphna Oyserman, CSW, is professor, School of Social Work and Institute for Social Research, University of Michigan. This study was supported by a research grant from the National Institute of Mental Health, R01-54321, Mental Health Services Research Branch.

Original manuscript received January 22, 2003

Final revision received April 27, 2004

Accepted June 29, 2004 
Copyright of Social Work Research is the property of National Association of Social Workers and its content may not be copied or emailed to multiple sites or posted to a listserv without the copyright holder's express written permission. However, users may print, download, or email articles for individual use. 